УДК 338.984

$10.17213 / 2075-2067-2020-5-203-208$

\title{
О ПРОБЛЕМАХ ЕДИНООБРАЗНЫХ ПОДХОДОВ К СТРАТЕГИЧЕСКОМУ ПЛАНИРОВАНИЮ НАУЧНО-ТЕХНОЛОГИЧЕСКОГО РАЗВИТИЯ РОССИИ
}

\author{
(C) 2020 г. А. Ю. Пинчук
}

\section{Московский государственный технологический университет «СТАНКИН», 2. Москва, Россия}

Цель статьи заключается в поиске единообразия концептуального и нормативно-правового регулирования научно-технологического развития России.

Результаты исследования. Рассмотрены технологии, обеспечивающие его реализацию, и их закрепление в документах стратегического планирования. Выявляется соотношение научно-технологического развития и обеспечения начиональной безопасности. В стратегическом планировании России сложились разнонаправленные представления о конкретных направлениях научно-технологического развития России. Динамика вызовов и угроз требует от органов государственной власти России большей гибкости и своевременности реагирования.

Перспективы исследования. Современная обстановка требует корректив Стратегии научно-технологического развития и гармонизации ее положений с другими документами стратегического планирования и, в первую очередь, со Стратегией национальной безопасности.

Ключевые слова: научно-технологическое развитие; индустрия 4.0; ичифровая экономика; нормативное регулирование.

\section{PROBLEMS OF UNIFORM APPROACHES TO STRATEGIC PLANNING OF SCIENTIFIC AND TECHNOLOGICAL DEVELOPMENT IN RUSSIA}

\section{(C) 2020 A. Y. Pinchuk}

\section{Moscow State University of Technology «STANKIN», Moscow, Russia}

The purpose of the article is to find uniformity in the conceptual and legal regulation of scientific and technological development in Russia.

Research result. The technologies that ensure its implementation and their consolidation in strategic planning documents are considered. The correlation between scientific and technological development and national security is revealed. In the strategic planning of Russia, there are multidirectional ideas about specific areas of scientific and technological development of Russia. The dynamics of challenges and threats require more flexibility and timely response from the Russian state authorities.

Prospects of the study. The current situation requires adjustments To the strategy of scientific and technological development and harmonization of its provisions with other strategic planning documents and, first of all, with the national security Strategy. 
Key words: scientific and technological development; industry 4.0; digital economy; regulatory regulation.

Введение. Как добиться того, чтобы многообразие концептуальных и программно-стратегических документов развития России не компенсировалось их слабой связью с реальной жизнью? И почему мы вообще наблюдаем эту картину? Что в таком случае является тем рычагом, с помощью которого можно перевернуть если не мир, то, во всяком случае, создать реальные механизмы ускорения государственного прогресса, а в ряде случаев и остановку деструкции? Представляется, что речь может идти о научно-технологическом развитии, направленном на формирование современного народного хозяйства на основе цифровой экономики и ускоренное развитие производственного сектора.

Цифровая экономика и индустрия 4.0. При этом следует иметь в виду, что распространенный сегодня бренд цифровой экономики получил существенное ускорение к распространению благодаря маркетинговому ходу немецкой компании «Сименс», которая при поддержке других крупных немецких корпораций в 2011 году заявила о наступлении новой (четвертой) технологической революции и в этой связи предложила концепцию «Индустрия 4.0» $[1,2]$.

Данный подход лег в основу продвижения новых подходов и услуг немецких компаний, объединенных содержанием данной концепции, в основе которых были выделены следующие технологические платформы:

- промышленный Интернет вещей (датчики и оборудование на производстве объединены в одну сеть иерархической структурой и подчинены единой системе управления производством);

- дополненная реальность (применима для различных целей, в том числе при выборе частей различных конструкций на складе, отображении инструкций по ремонту и обслуживанию оборудования и т.д.);

- большие данные (BIG DATA) и бизнес-аналитика (аналитика, основанная на работе с большим объемом данных, что позволяет оптимизировать качество продукции, экономить энергию и повысить работоспособность оборудования);

— «облачные технологии» (применяются ведущими компаниями при решении многих задач, в частности, в программном обеспечении своей производственной деятельности и т.д.). Необходимость обработки больших баз данных требует дальнейшего совершенствования «облачных сервисов»;

— автономные роботы (т.е. гибкие и функционально независимые);

- горизонтальная и вертикальная интеграция систем (организация тесного взаимодействия как на различных уровнях внутри предприятия, так и между предприятиямипартнерами по производственному циклу);

- информационная безопасность (защищенный доступ, надежная связь, полный контроль доступа к сетям управления);

- аддитивное производство (освоение в промышленности аддитивных технологий, в том числе применение 3D-печати для прототипирования и производства отдельных деталей);

- цифровое моделирование, являющееся одним из базовых направлений реализации программы «Индустрия 4.0», которое будет активно применяться в производственных процессах, в том числе путем использования актуальных данных, получаемых с помощью виртуальной модели окружающего физического мира $[3,4]$.

В этой связи в практику вошли цифровые производственные ячейки, безлюдное производство, цифровые производственные двойники, цифровые стандарты, широкое внедрение бизнес-процессов на основе киберфизических систем и т.п.

Следует отметить, что официального закрепления концепт «Индустрия 4.0.» в Российской Федерации не получил, хотя и активно используется в научной и производственной сферах. А вот взаимоувязанная идеология в виде цифровой промышленности и цифровой экономики закреплена в соответствующем Паспорте национального проекта «Национальная программа "Цифровая экономика Российской Федерации”», утверж- 
денном протоколом заседания президиума Совета при Президенте Российской Федерации по стратегическому развитию и национальным проектам №7 от 4 июня 2019 г. [5].

Одновременно с этим российским государством сформировано стратегическое представление о своем научно-стратегическом развитии и приоритетах в этой связи, отраженное в Стратегии научно-технологического развития, где были сформулированы приоритеты научно-технологического развития Российской Федерации. Более того, в России приняты усилия по определению конкретных направлений реализации научнотехнологической стратегии. Так, выделена площадка, получившая название «Новая технологическая инициатива», определены конкретные технологические решения, которые в будущем станут так называемыми «прорывными». В послании Федеральному собранию 4 декабря 2014 года Президент России Владимир Путин обозначил Национальную технологическую инициативу одним из приоритетов государственной политики. Миссией НТИ определено объединение бизнеса, вузов, институтов развития, экспертных и профессиональных сообществ, органов власти.

Указанный подход расширил представления о технологических перспективах. Однако дальнейшее концептуальное и нормативно-правовое регулирование реализации этих проектов опять ушло в сторону цифровой экономики в российской интерпретации, то есть в самостоятельную ИТ-сферу. Здесь, однако, следует обратить внимание на разобщенность и некоторую несогласованность в выделении стратегических для государства технологий. Мы наблюдаем три верхнеуровневых государственных стратегических основы, каждая из которых является приоритетной для органов власти и научно-технологического сообщества, затрагивает принципиальные проблемы развития и безопасности государства. Но в Стратегии национальной безопасности выделено 9 направлений, в Новой технологической инициативе их 10, а в Стратегии научно- технологического развития - 7 .

Сравнительный анализ государственных стратегических основ научно-технологического развития. Попытаемся сравнить государственные стратегические осно- вы научно-технологического развития на основе обращения к Стратегии национальной безопасности, к Новой технологической инициативе и к Стратегии научно-технологического развития (табл. 1).

Как мы видим, некоторые технологии не совпадают, дублирование частичное и разнонаправленное, много пробелов. При этом решения, принимаемые российским государством в сфере науки и технологий, ситуативно базируются на различных стратегических установках.

Например, летом 2020 года в нашей стране серьезное внимание было уделено генетическим исследованиям. Президент России Владимир Путин на совещании о развитии генетических технологий в России поручил создать национальную базу генетической информации. Проводимые Президентом совещания широко освещались СМИ как одно из важнейших направлений научно-технологического развития страны. По итогам предусмотрено создание отечественного лабораторного и научного оборудования, позволяющего проводить исследования мирового уровня в области генетических технологий; разработка школьных учебных курсов и модулей по генетике, организация повышения квалификации педагогов; создание национальных биоресурсных центров по направлениям федеральной научно-технической программы развития генетических технологий на 2019-2027 годы; обеспечение потребности в кадрах в области разработки и применения генетических технологий.

Как мы видим в приведенной таблице, генетические исследования отсутствуют в Стратегии научно-технологического развития и направлениях Научно-технологической инициативы (хотя в последней упоминаются «генетика, биотехнологии»). Можно было бы предположить, что генетика является частью приоритета «в) переход к персонализированной медицине». Однако генная инженерия это и, например, ГМО. Но это уже пищевые продукты с улучшенными свойствами, что относится к приоритету «г) создание безопасных и качественных, в том числе функциональных, продуктов питания». Возможно, логика базируется на том, что это смежная для приоритетов технология. Однако генная инженерия присутствует ключевым и са- 
Таблица 1

Сравнительный анализ государственных стратегий научно-технологического развития

\begin{tabular}{|c|c|c|}
\hline $\begin{array}{c}\text { Стратегия } \\
\text { научно-технологического развития }\end{array}$ & $\begin{array}{c}\text { Новая технологическая } \\
\text { инициатива }\end{array}$ & $\begin{array}{l}\text { Стратегия нац. } \\
\text { безопасности }\end{array}$ \\
\hline $\begin{array}{l}\text { Цифровые, интеллектуальные производс- } \\
\text { твенные технологии; роботизированные } \\
\text { системы; новые материалы; способы } \\
\text { конструирования; создание систем обра- } \\
\text { ботки больших объемов данных; машин- } \\
\text { ное обучение; искусственный интеллект }\end{array}$ & $\begin{array}{l}\text { Новые производственные } \\
\text { технологии; сенсорика и ком- } \\
\text { поненты робототехники; ней- } \\
\text { ротехнологии, технологии } \\
\text { виртуальной и дополненной } \\
\text { реальности; искусственный } \\
\text { интеллект; системы распр-- } \\
\text { деленного реестра, или блок- } \\
\text { чейн; квантовые технологии; } \\
\text { «Большие данные» (Big Data) }\end{array}$ & $\begin{array}{l}\text { Робототехника; } \\
\text { нан о тех н ол о- } \\
\text { гии; когнитивные } \\
\text { технологии; при- } \\
\text { родоподобные } \\
\text { конвергентные } \\
\text { технологии) }\end{array}$ \\
\hline $\begin{array}{l}\text { Экологически чистая, ресурсосберегаю- } \\
\text { щая энергетика, повышение эффектив- } \\
\text { ности добычи и переработки углеводо- } \\
\text { родного сырья, формирование новых } \\
\text { источников, способов транспортировки } \\
\text { и хранения энергии }\end{array}$ & $\begin{array}{l}\text { Новые и портативные источ- } \\
\text { ники энергии }\end{array}$ & \\
\hline $\begin{array}{l}\text { Персонализированная медицина, техно- } \\
\text { логии здоровьесбережения, в том числе } \\
\text { за счет рационального применения ле- } \\
\text { карственных препаратов (прежде всего } \\
\text { антибактериальных) }\end{array}$ & $\begin{array}{l}\text { Технологии управления } \\
\text { свойствами биологических } \\
\text { бъектов }\end{array}$ & $\begin{array}{l}\text { Генная инжене- } \\
\text { рия; биологичес- } \\
\text { кие технологии }\end{array}$ \\
\hline $\begin{array}{l}\text { Высокопродуктивное и экологически } \\
\text { чистое агро- и аквахозяйство, системы } \\
\text { рационального применения средств хи- } \\
\text { мической и биологической защиты сель- } \\
\text { скохозяйственных растений и животных, } \\
\text { хранение и эффективная переработка } \\
\text { сельскохозяйственной продукции, созда- } \\
\text { ние безопасных и качественных продук- } \\
\text { тов питания }\end{array}$ & & \\
\hline $\begin{array}{l}\text { Противодействие техногенным, биоген- } \\
\text { ным, социокультурным угрозам, терро- } \\
\text { ризму и идеологическому экстремизму, а } \\
\text { также киберугрозам и иным источникам } \\
\text { опасности для общества, экономики и го- } \\
\text { сударства }\end{array}$ & & \\
\hline $\begin{array}{l}\text { Интеллектуальные транспортные и теле- } \\
\text { коммуникационные системы, международ- } \\
\text { ные транспортно-логистические системы, } \\
\text { освоение и использование космического и } \\
\text { воздушного пространства, Мирового океа- } \\
\text { на, Арктики и Антарктики }\end{array}$ & $\begin{array}{l}\text { Технологии беспроводной } \\
\text { связи }\end{array}$ & $\begin{array}{l}\text { Информационные } \\
\text { и коммуникацион- } \\
\text { ные технологии }\end{array}$ \\
\hline
\end{tabular}


Окончание таблицы 1

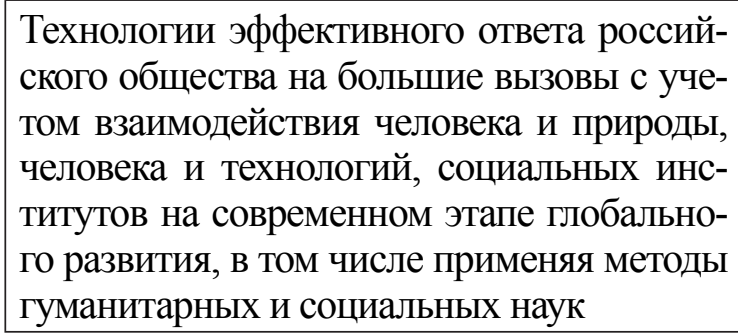

Технологии эффективного ответа российского общества на большие вызовы с учетом взаимодействия человека и природы, человека и технологий, социальных институтов на современном этапе глобального развития, в том числе применяя методы гуманитарных и социальных наук

мостоятельным направлением в Стратегии национальной безопасности. То есть в двух одноуровневых документах стратегического планирования данная технология имеет разный уровень фиксации, если вообще полноценно присутствует, при том что руководство страны ситуативно определяет важнейшей технологией направление, которое в ключевом документе, вероятно, забыли прямо упомянуть (или на момент написания проекта Стратегии научно-технологического развития недооценили его значимость).

С другой стороны, Искусственному интеллекту, отсутствующему в Стратегии национальной безопасности и предусмотренному Стратегией научно-технологического развития и Научно-технологической инициативой, государством уделено большое внимание. О его развитии принят отдельный Указ Президента России от 10 октября 2019 г. №490 «О развитии искусственного интеллекта в Российской Федерации», а решением Правительства России более 60 федеральных министерств и ведомств подготовят «дорожные карты» по внедрению решений на основе искусственного интеллекта. Именно такая «наступательность» вполне логична при реализации согласованной государственной стратегии. При этом маловероятно, что столь значимый сегмент научнотехнологического развития, затрагивающий важнейшие вопросы безопасности общества и государства, находится вне сферы национальной безопасности.

Заключение. Таким образом, мы наблюдаем рассогласованность в методологии и подходах. Это свидетельствует о серьезных недоработках в вопросах формирования единой системы нормативно-правового регулирования научно-технологического развития Российской Федерации во взаимосвязи с обеспечением национальной безопасности и трансформацией социально-политических процессов.

В этой связи можно сделать следующие выводы. Во-первых, в стратегическом планировании России сложились разнонаправленные представления о конкретных направлениях научно-технологического развития России. Во-вторых, динамика вызовов и угроз требует от органов государственной власти России большей гибкости и своевременности реагирования. Современная обстановка требует корректив Стратегии научно-технологического развития и гармонизации ее положений с другими документами стратегического планирования, и, в первую очередь, со Стратегией национальной безопасности.

\section{Литература}

1. Революционный темп: Индустрия 4.0. Концепция «Индустрия 4.0» приживается на отечественном рынке [Электронный ресурс] - Режим доступа: http://siemens.rbc.ru/ article2.html (Дата обращения: 12.09.2020).

2. Цифровая трансформация экономики и промышленности: проблемы и перспективы / под ред. д-ра экон. наук, проф. А. В. Бабкина. - СПб: Изд-во Политехн. ун-та, 2017. - $807 \mathrm{c}$.

3. Плакиткин Ю.А. Программы «Индустрия 4.0» и «Цифровая экономика Российской Федерации» - возможности и перспективы в угольной промышленности // Горная Промышленность. — 2018. — №1 (137). C. 22-28.

4. Рябинская С.С. Информатизация общества в России: особенности формирования и сопутствующие угрозы // Концепт. 2013. - T. 4. - С. 276-280.

5. Харичкин И. К. Проблемы обеспечения национальной безопасности в условиях ста- 
новления цифровой экономики России // Аллея Науки. - 2018. - №6 (22). - С. 703-709.

6. Развитие цифровой экономики в России как ключевой фактор экономического роста и повышения качества жизни населения: монография. - Нижний Новгород: Профессиональная наука, 2018. - 131 с.

\section{References}

1. Revoljucionnyj temp: Industrija 4.0. Koncepcija «Industrija 4.0» prizhivaetsja na otechestvennom rynke [Revolutionary pace: industry 4.0. the Concept of "Industry 4.0» takes root in the domestic market] [Jelektronnyj resurs] - URL: http://siemens.rbc.ru/article2. html (Date accessed: 12.09.2020).

2. Cifrovaja transformacija jekonomiki i promyshlennosti: problemy i perspektivy [Digital transformation of the economy and industry: problems and prospects] / In A. V. Babkina (eds.). - Saint-Petersburg: Izd-vo Politehn. unta, 2017. - $807 \mathrm{p}$.

3. Plakitkin Ju. A. Programmy «Industrija 4.0» i «Cifrovaja jekonomika Rossijskoj Federacii» — vozmozhnosti i perspektivy v ugol'noj promyshlennosti [Programs «Industry 4.0» and «Digital economy of the Russian Federation»opportunities and prospects in the coal industry] // Gornaja Promyshlennost' [Mining Industry]. — 2018. — №1 (137). — Pp. 22-28.

4. Rjabinskaja S.S. Informatizacija obshhestva v Rossii: osobennosti formirovanija i soputstvujushhie ugrozy [Informatization of society in Russia: peculiarities of formation and related threats is considered] // Koncept. - 2013. Vol. 4. - Pp. 276-280.

5. Harichkin I.K. Problemy obespechenija nacional'noj bezopasnosti $\mathrm{v}$ uslovijah stanovlenija cifrovoj jekonomiki Rossii [Problems of national security in the conditions of formation of the digital economy of Russia] // Alleja Nauki [Avenue of Science]. — 2018. — №6 (22). Pp. 703-709.

6. Razvitie cifrovoj jekonomiki v Rossii kak kljuchevoj faktor jekonomicheskogo rosta i povyshenija kachestva zhizni naselenija: monografija [Digital economy development in Russia as a key factor for economic growth and improved quality of life: monograph]. - Nizhnij Novgorod: Professional'naja nauka, 2018. $131 \mathrm{p}$.

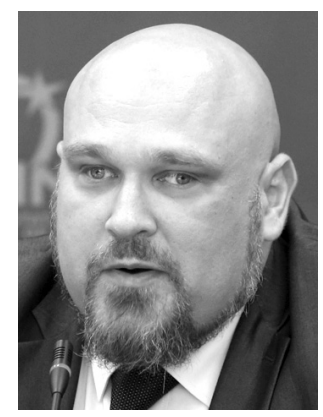

Пинчук Андрей Юрьевич - доктор политических наук, первый проректор Московского государственного технологического университета «СТАНКИН».

Pinchuk Andrey Yurevich - Doctor of Political Sciences, first Vice-rector, Moscow State University of Technology «STANKIN».

127055, г. Москва, Вадковский пер., 3А

3A Vadkovsky ln., 127055, Moscow, Russia

E-mail: pakt77@mail.ru 